$\begin{array}{cl}\text { Türkiye Tarımsal Araştırmalar Dergisi } & \text { Turk J Agric Res } \\ \text { http://dergi.siirt.edu.tr } & \text { (2016) 3: 74-78 } \\ \text { OTÜTAD } & \text { ISS: 2148-2306 } \\ \text { Arastırma Makalesi / Research Article } & \text { 10.19159/tutad.74018 }\end{array}$

\title{
Türkiye’de Kivi Üretici Birliklerinin Mevcut Durumu, Sorunları ve Çözüm Önerileri
}

\author{
Erdal SIRAY ${ }^{1}$, Osman KILIÇ ${ }^{2 *}$ \\ ${ }^{l}$ Findık Araștrrma Enstitüsü, Giresun, TÜRKIYE \\ ${ }^{2}$ Ondokuz Mayls Üniversitesi, Ziraat Fakültesi, Tarım Ekonomisi Bölümü, Samsun, TÜRKIYE
}

Geliş Tarihi/Received: 02.02 .2016

Kabul Tarihi/Accepted: 15.03 .2016

*Sorumlu yazar/Corresponding author: okilic@omu.edu.tr

Özet: Tarımla ilgili yeni teknolojilerin benimsenmesi ve uygulamaya aktarılmasında, üretici birliklerine önemli görevler düşmektedir. Türkiye'de son yıllarda kivi üretiminin ve buna bağlı olarak iç tüketimin artmasında birliklerin büyük katkısı olmuştur. Kivi üretici birliklerinin en önemli görevi, üyelerine ürünlerin pazarlanmasında yardımcı olmakla birlikte, üretim tekniğiyle ilgili sorunların çözümüne de katkı sağlamaya çalışmaktır. Araştırma verilerini, 12 kivi üretici birliğiyle yapılan anketler oluşturmaktadır. Araştırma sonuçlarına göre, anket yapılan kivi üretici birliklerinin en önemli sorunu mali konularda sıkıntı yaşamalarıdır. Gelirlerinin \% 79.4'ünü aidatlardan sağlayan birlikler, sınırlı bütçeleri nedeniyle görevlerini yeterince yerine getirememektedirler. Birliklere göre kivi konusunda yaşanan başlıca sorunlar, üretim tekniğiyle ilgili bilgi eksikliği ve bunu çözecek yeterli teknik personelin olmamasıdır. Kivide iç talebin yeterli olmasından dolayı, pazarlama sorununun olmadığı belirtilmiştir. Ancak soğuk hava deposu sıkıntısı nedeniyle, ürünün en kısa sürede elden çıkarılması gerektiği için istenilen fiyatlardan satılamadığı ifade edilmiştir.

Anahtar Kelimeler: Kivi, kivi üreticileri, üretici birlikleri

\section{Current Situation, Problems and Solution Proposals of Kiwi Producer Associations in Turkey}

\begin{abstract}
Producer associations have an important role in adoption and implementation of new agricultural technologies. In Turkey, associations have contributed significantly to increase of kiwi production and its consumption in recent years. The most important function of kiwi producer associations is to assist their members in marketing of products as well as to try to provide solutions to problems related to kiwi production techniques. The data of this research was obtained from the 12 kiwi producer associations. According to the research results, the most important problem of kiwi producer associations is having financial difficulties. The associations, getting $79.4 \%$ of their incomes from the subscriptions, are unable to sufficiently perform their duties due to their limited budgets. The associations have indicated that the main problems in kiwi production are lack of knowledge for production techniques and qualified technical staff. There is no marketing problem of the product due to adequate domestic demand. But, the products should be disposed immediately due to lack of cold storage facilities and they are not sold at desired price.
\end{abstract}

Keywords: Kiwi, kiwi producers, producer associations

\section{Giriş}

Günümüzde, gelişmiş ülkelerin ulaştıkları sosyal ve ekonomik refahın temelinde tarım sektöründeki gelişmeler yatmaktadır. Tarım, işgücü ve sermaye katkısı sağlayan bir sektör olarak ülkenin sanayileşmesinde büyük rol oynamaktadır. Tarımın ve tarımsal sanayinin gelişmesinde, üretici örgütlerinin önemli katkısı vardır. Üretimden pazarlamaya kadar örgütlü bir yapıda hareket eden üreticiler, kendileri ve ülkeleri için yarar 
sağlamışlar ve güçlü üretici örgütleri sayesinde tarım-sanayi entegrasyonunu başarıyla kurmuşlardır (Köroğlu, 2003). Örgütler pazarlamadaki etkin rolleri sayesinde, pazardan daha fazla pay almışlar ve kâr marjlarını artırma imkânına kavuşmuşlardır.

Örgütlenme; ortak yaşama, birlikte hareket etme, işbirliği yapma ve kurumsallaşma olarak tanımlanabilir. Bir ülkenin sahip olduğu siyasi ve ekonomik potansiyeli ile gelişmişlik düzeyi örgütsel yapısıyla yakından ilgilidir. Bir toplumda örgütlenmenin yaygın ve güçlü olması, gelişmişliğin bir göstergesi olarak kabul edilmektedir. $\mathrm{Bu}$ açıdan incelendiğinde, gelişmiş batı dünyasının örgütlü bir yapıya sahip olduğunu belirtebiliriz (Rehber, 2007). Avrupa Birliği'nde üretici örgütleri çiftçilerin gönüllü katılımlarına dayanmakta, ancak devletin onayı ile kurulmaktadır. Kuruluşu için örgütün belli bir üye sayısına ulaşmış olması, asgari bir miktarda ürün pazarlıyor olması, üyelerine çevre dostu üretim yapmaktan, depolama, tasnif, pazarlama, defter tutma ve bütçe tekniğine kadar çeşitli konularda bilgi aktarması ve bir eylem planı yapmış olması gibi kurallar aranmaktadır (Köroğlu, 2003).

Türkiye'de tarım sektöründeki küçük aile işletmelerinin büyük bir kısmı, sadece tüketim ihtiyaçlarını karşılayabilecek düzeyde gelire sahiptirler. Küçük işletmelerin finansman kuruluşlarından kredi sağlayarak yeni yatırımlarla işletmelerini büyütmeleri zordur. Bu bakımdan, Türkiye gibi çoğunluğu küçük işletmelerden oluşan tarım sektöründe üretici örgütlenmesi büyük önem taşımaktadır. Kırsal kesimde üretici örgütlenmesinin temel amacı, çiftçi ve ailelerinin yaşam düzeyini ve kalitesini yükseltmek ve üreticilerin pazardaki konumunu güçlendirmektir (Özdemir ve ark., 2010). Türkiye'de üretici örgütlerinin güçlenmesi, büyük aracı ve tefecilerle rekabet edebilmesi, diș ticarette ve sanayide etkili olabilmesi ve hatta Avrupa Birliği ülkelerindeki çiftçi kooperatifleri vb üretici örgütleri ile bütünleşebilmesi için, bunların demokratik ve özerk üst örgütlerini en kısa zamanda olușturmaları ve aynı zamanda dikey bütünleşmeye gitmeleri gerekmektedir (İnan ve ark., 2000).

Türkiye kivi üretiminde dünyada belli başlı üretici ülkeler arasında yer almaktadır (Anonymous, 2015). Türkiye'de kivi dikim alanı ve üretim miktarı, artan iç talebe bağlı olarak son yıllarda büyük artış göstermiştir. Kivi dikim alanı, son on yılda (2005-2014) yaklaşık 2.2 kat artış göstermiş, verimdeki iyileşmeden dolayı üretim miktarındaki artış ise daha yüksek olmuştur. Türkiye'de kivi yetiştiriciliği Marmara ve Karadeniz Bölgeleri'nde yoğun olarak yapılmaktadır. Son beş yılın ortalamasına göre (2010-2014) kivi dikim alanı ve üretim miktarı yönünden, en yüksek payı sırasıyla Yalova, Rize, Ordu ve Giresun illeri almaktadır. Beş yıllık ortalama kivi dikim alanının yaklaşık \% 23'ü, üretimin ise \% 39'u Yalova'ya aittir (Anonim, 2015).

Türkiye'de ticari anlamda kivi yetiştiriciliği son yıllarda önem kazanmasına rağmen, kivi konusunda çok fazla araştırmanın yapıldığı söylenemez. Kivi konusunda yapılan sinırl sayıdaki araștırmanın büyük bir kısmı ise üretim tekniğiyle ilgilidir. Benzer konuda yapılmış bir çalışmada, Samsun'daki tarımsal örgütlerin yapısal sorunları ortaya konulmuştur (Aydoğan ve Yulafçı, 2013).

Bu araştırmanın amacı, Türkiye'de son yıllarda gelişme göstererek üreticiler için ciddi bir gelir kaynağı olan kivi yetiştiriciliğinde önemli görevler üstlenen kivi üretici birliklerinin, mevcut durumlarını ortaya koymak ve sorunlarına çözüm önerileri getirmektir.

\section{Materyal ve Yöntem}

Araştırmanın esas materyalini, kivi üretici birliklerinin başkan ya da yönetim kurulu üyeleriyle Nisan 2014'te yapılan anketler oluşturmaktadır. Birlik sayısı az olduğu için, tam sayım yöntemiyle toplam 12 anket uygulanmıştır. Anketler birliklerin 8'inde birlik başkanı, 4'ünde ise birlik başkanlarıyla görüşme imkânı bulunamadığı için yönetim kurulu üyeleriyle yapılmıştır.

\section{Bulgular ve Tartışma}

\section{1. İdari yapı}

Kivi üretici birliklerinden 9'u kendilerine ait hizmet binası olmadan faaliyetlerini sürdürürken, diğerleri kiraladıkları binalarda hizmet vermektedirler. Araştırma kapsamındaki ilk kivi üretici birliği 2005 yılında kurulmuştur. Kivi üretici birliklerinin ilk kurulma fikrinin 11'inde birlik üyeleri, 1'inde ise tarımsal kuruluşların girişimiyle ortaya çıktığı belirtilmiştir. Birlik başkanı ve yönetim kurulu üyelerinden oluşan 12 kişiye göre, birliklerin kurulma amaçları Tablo 1 'de verilmiştir. Birliklerin kurulma amaçları içinde \% 75 ile en büyük payı ürünün yüksek fiyatla satılması gösterilmiştir.

Birliklerde sürekli çalışan personel bulunmamaktadır. Birliklerden sadece biri, her yıl hasat sonrası dönemde belli bir süre için personel çalıştırdığını belirtmiştir. Birliklerin tamamında üyelerle irtibat telefon aramalarıyla sağlanırken; 
bunun yanında kisa mesaj hizmeti (Short Message Service, SMS), belediye anonsu ve internet yoluyla da haberleşme sağlanmaktadır. Birliklerden 10'u genel kurullarını her yıl düzenli yaparken, 2'si aksattıklarını belirtmişlerdir.

Tablo 1. Birliklerin kurulma amaçları (\%)

\begin{tabular}{lr}
\hline Ürünü yüksek fiyatla satmak & 75.0 \\
Üreticilerin ekonomik durumlarını güçlendirmek & 33.3 \\
Kaliteli ürün üretmek & 33.3 \\
Kivinin alternatif gelir kaynağı olmasını sağlamak & 16.7 \\
Soğuk hava deposu kurmak & 16.7 \\
Danışmanlık hizmeti vermek & 8.3 \\
İleriki yıllarda organik tarıma geçmek & 8.3 \\
\hline ": Bir kiși birden fazla soruya cevap vermiștir. &
\end{tabular}

Birlik başkanlarının yaş ortalaması 54 olup, en genç başkan 37, en yaşlısı ise 70 yaşındadır. Başkanların eğitim durumları incelendiğinde 2'si ilkokul, 6'sı lise, 4'ü yükseköğretim mezunudur.

Birliklerde başkanlar genel kurulda seçimle başkan olmaktadırlar. Ancak birliklerin hiç birinde bugüne kadar çoklu adayla seçim yapılmamıştır. Başkanlar gönüllülük esasıyla ve tek aday gösterilmek suretiyle seçilmişlerdir. Başkanların 7'sinin ikinci dönem, 5'inin ise ilk dönem başkanlıklarıdır. Birlik başkanlarının 6'sı özel ya da kamudan emekli iken, 2'si memur, 2'si esnaf, 2'si de çiftçilik yapmaktadır. Birlik başkanlarından 9'u, daha önce özel ya da kamuda yöneticilik kademelerinde bulunmuşlardır. Başkanlardan sadece 1'i daha önce birlik yönetimiyle ilgili eğitim almıştır.

\subsection{Gelir-gider durumu}

Anket yapılan birliklerin 2013 yılına ait gelirgider durumları Tablo 2'de verilmiştir. Birlik başına kâr 2009.8 TL olup, bu rakam gelirin \% 26.9'una karşılık gelmektedir. Birliklerin 2'sinde gelirler giderleri karşılamamaktadır. Birlik başına düşen gelirin \% 79.4'ünü aidatlar oluşturmaktadır. Birliklerde giderlerin \% 25.1 ile en büyük kısmını elektrik-su, bunu \% 23.4 ile muhasebeci ücreti takip etmektedir. Aydoğan ve Yulafçı (2013), Samsun'daki tarımsal örgütlere ait gelirin \% 75'inin aidatlardan oluştuğunu ortaya koymuşlardır.

Birlik yöneticileri üyelik aidatı ödeme konusunda üyelerle sorun yaşadıklarını belirtmişlerdir. Birliklerin sadece 3'ünde aidatların tamamı toplanmış, 8'inde sınırlı miktarda toplanmış, 1 'inde ise hiç toplanamamıştır. Üyeler tarafından yıllık aidatların sınırlı miktarda ya da hiç ödenmemesine neden olarak, yöneticilerden 4'ü üreticilere ait ürünün az ya da hiç olmamasını gerekçe göstermişlerdir. Bunun yanında 3'ü üyelerinin birlik faaliyetlerinden fayda sağlamadıklarını, 2'si ise birliklerin pazarlamada henüz aktif olamamasını gerekçe olarak belirtmişlerdir.

Tablo 2. Gelir-gider durumu (TL/birlik)

\begin{tabular}{llrr}
\hline & & $(\mathrm{TL})$ & $\mathbf{( \% )}$ \\
\hline \multirow{4}{*}{ Gelirler } & 5939,1 & 79.4 \\
& Aidatlar & 208,3 & 2.8 \\
& Bağışlar & 1333,3 & 17.8 \\
& Depo katılım payı & 7480,7 & 100.0 \\
& Toplam & 83,3 & 1.5 \\
& Personel & 1066,7 & 19.5 \\
& İşçilik & 58,3 & 1.1 \\
& Nakliye & 41,7 & 0.8 \\
& Depolama & 1375,0 & 25.1 \\
& Elektrik, su & 237,5 & 4.3 \\
Giderler & Sigorta, vergi & 120,8 & 2.2 \\
& Haberleşme & 650,0 & 11.9 \\
& Kira & 1279,2 & 23.4 \\
& Muhasebeci ücreti & 416,7 & 7.6 \\
& Tamir-bakım & 141,7 & 2.6 \\
& Yönetim & 5470,9 & 100.0 \\
& Toplam & 2009,8 & - \\
Kâr & & &
\end{tabular}

\subsection{Eğitim ve danışmanlık hizmeti}

Anket yapılan 12 birlikten 7'si üyelerine budama, dikim sistemleri, sulama ve bahçe tesisi gibi üretim tekniğiyle ilgili konularda Gıda, Tarım ve Hayvancılık İl ve İlçe Müdürlükleri ile Araştırma Enstitüleri'nde çalışan tarım danışmaları vasıtasıyla eğitim hizmeti sunmaktadırlar. Ayrıca meyve oluşumu, şekerlenme, hasat, depolama ve ambalajlama gibi konularda da eğitim toplantıları düzenlenmektedir. Geriye kalan 5 birlikte ise üyelere kiviyle ilgili teknik destek verilmemektedir. Birlikler tarafından üyelere girdi desteği verilmediği gibi, birliklerde tarım danışmanı istihdamı da söz konusu değildir.

\subsection{Pazarlama hizmeti}

Birlikler, üyelerinin kivi üretimiyle ilgili istatistiklerini tutmamaktadırlar. Birliklerin 6's1 üyelerine ait ürünlerin, üye olmayanlarınkinden daha kaliteli olduğunu ifade etmişlerdir. Buna neden olarak, birliklerden 3'ü üyelerinin kimyasal ilaç kullanmadıkları için kivinin tat ve aromasının daha iyi olduğunu belirtmişlerdir. Birliklerden 3’ü ise, üyelerine ait bahçelerin bakımlı olduğu için daha kaliteli ürün elde ettiklerini ifade etmişlerdir.

Birliklerden 8'i Türk Standartları Enstitüsü (TSE)'nün kivi satışına getirdiği standartlara (Anonim, 2005) uymakta, 1'i bu standartlara yakın değerler kullanmakta, diğer 3'ü ise standart kullanmamaktadırlar.

Birliklerin tamamı piyasadaki fiyatın belirlenmesinde birliklerin etkisi nedeniyle, ürün 
fiyatlarının bir miktar yükseldiğini ifade etmişlerdir. Aynı zamanda birlik olarak ortak hareket etmekle toplu satış şanslarının daha fazla olduğunu belirtmişlerdir.

Birliklerden sadece 1'inde soğuk hava deposu mevcuttur. Birliklerden 1 'i yılda 1 ay depo kiralamakta, 10'u ise maliyeti karşılamadığından dolayı depo kiralayamadıklarını ifade etmişlerdir.

Birliklerden 7'si üyelerine ait ürünlerle ilgili reklam yapmaktadırlar. Reklam yapan birliklerden 4'ü internet, 2'si televizyon, 1'i de gazete ve festival yoluyla reklam yapmaktadırlar.

\subsection{Sorunlar ve çözüm önerileri}

Anket yapılan birlik yöneticileri kivi yetiştiriciliğinde girdilerin pahalı olmasını, uygun doz ve zamanda girdi kullanılmamasını, toprak ve bitki analizine önem verilmemesini başlıca sorunlar olarak ifade etmişlerdir.

Birlikler, eğitim konusunda Gıda, Tarım ve Hayvancılık İl ve İlçe Müdürlükleri'nden destek almaktadırlar. Ancak yetiştiricilik konusunda yeterli teknik uzmanın olmamasından dolayı, verilen desteğin amacına ulaşamadığı ifade edilmiştir. Bundan dolayı birlikler, üniversitelerin kivi konusunda daha fazla araştırma yaparak teknik konularda üreticilere destek vermesi gerektiğini belirtmişlerdir.

Birlik yöneticilerine göre sulama tesisi kurmak pahalı olduğu için, devletin sulama tesisi kuranlara destek vermesi gerektiğini ifade etmişlerdir. Birlikler pazarlamada en önemli sorun olarak, yeterli sayıda soğuk hava deposunun olmamasını ileri sürmüşlerdir. Bunun dışında ulaşımın zorluğunu ve hallerin düzgün çalışmamasını da pazarlamada önemli sorunlar arasında göstermişlerdir. Birliklerin soğuk hava deposu konusundaki düşünceleri, belediyelerin bölgelere soğuk hava deposu yapması ve bunları üreticilere kiralaması şeklindedir. Ayrıca kivi ithalatının önlenmesi ve pazarlamanın birlikler aracılığıyla yapılması ortak görüş olarak belirtilmiştir.

Birliklerden 7'si birliklerin geleceğini olumsuz görmektedirler. Birliklerden 4'ü, bu sorunlarla devam edilmesi halinde birliklerin yakın gelecekte kapanabileceğini belirtmişlerdir. Geliri olmayan 1 birlik ise, birliğin mali yükünün birlik başkanı tarafından karşılandığını ve borçları nedeniyle kapanmak üzere olduğunu ifade etmiştir. Aydoğan ve Yulafçı (2013), Samsun'daki tarımsal örgütler, faaliyetlerini gerçekleştirecek düzeyde bütçeye sahip olmadıkları için, yeni faaliyetlere giremediklerini ve beklentileri karşılayamadıklarını ifade etmişlerdir. Dolayısıyla bütçe yetersizliği, tarımsal örgütlerin genel problemi olarak karşımıza çıkmaktadır.

Anket yapılan birlik yöneticileri, birliklerin sorunlarını 8 başlık halinde özetlemişlerdir:

1. Devletin birliklere yeterli düzeyde desteği yoktur.

2. Birlikler devletin hibe ya da düşük faizli kredi desteklerinden yeterince yararlanamamaktadırlar.

3. Bölgelerde yeterli sayıda soğuk hava deposu bulunmamaktadir.

4. Kivi üretici birlikleri dağınık yapıdadırlar.

5. Mevcut vergi mevzuat1 birliklere uymamaktadir.

6. Birlikler yeterli gelir elde edemedikleri için denetimler birlikler için pahalı olmaktadır.

7. Kivi bahçesi tesis maliyeti yüksektir.

8. Kivide ithalat kontrolsüz ve zamansız yapılmaktadır.

\section{Sonuçlar}

Türkiye'de kivi üretici birliklerinin kuruluş tarihleri yeni olduğu için üye sayıları azdır. En eski birliğin 10 yıllık geçmişi vardır. Birliklerin kendilerine ait hizmet binaları olmadığı için, çeşitli kurumların binalarında geçici olarak hizmetlerine devam etmektedirler. En büyük gelir kalemi üye aidatları olan birlikler, giderlerini karşılamakta zorluk çekmekte ve zorunlu yatırımlarını yapamamaktadırlar.

Birlikler; üreticilerin birlikteliğini artırmak, ürünün daha yüksek fiyatla satılmasını sağlamak, kaliteli ürün üretmek gibi amaçlarla kurulmuş olmalarına rağmen, üyelerde birlikteliğin sağlandığ ve hedeflenen amaçlara ulaşıldığ 1 söylenemez.

Birlik üyelerine ait ürünlerin pazarlanmasında genellikle alıcılar bölgeye gelmekte ve pazarlıklar üretimin gerçekleştiği ortamda yapılmaktadır. Bu durum, görünüşte fiyat oluşumu için birlikler açısından olumlu gibi görünse de, alıcıların fiyat belirlemede rolü daha fazla olmaktadır. Soğuk hava deposunun yaygın olmaması, ürünlerin satışını kısıtlı zamana sıkıştırarak fiyat konusunda alıcıya mahkûm bırakmaktadır. Hâlbuki soğuk hava deposunun yaygın olması halinde, ürünün pazarlanması daha geniş zamana yayılacak, böylece üreticiler ürünlerini daha yüksek fiyatla satabilme imkânı elde edeceklerdir.

Kivi yetiştiriciliğiyle ilgili kültürel işlemlerin yapılmasında eksikliklerin olduğu anlaşılmaktadır. Toprak analizine dayalı gübre uygulamasinın az olmasının yanında, gübre ve ilaçlama konusunda yeterli teknik bilginin olmadığ 1 belirtilmiştir. $\mathrm{Bu}$ 
konuyla ilgili olarak üniversite ve araştırma kuruluşlarında bilimsel çalışmaların artırılması gerekmektedir.

Birliklerin yeterince desteklenmemesi, gelecekte kivi üretiminin azalmasına ve birliklerin kapanmasına sebep olacaktır. Bazı birlikler bu soruna işaret ederek, gelecekte kapanabileceklerini ifade etmişlerdir. Tarımda örgütlenmenin önemli olduğu günümüzde, birliklerin desteklenerek ayakta kalması ve yeni yatırımlarla üreticilere daha iyi hizmetler sunması gerekmektedir.

Kivi üretici birliklerinde sorunların birlikte çözülebileceği kurumsal bir sistem mevcut değildir. Genel olarak birlikler birbirlerinden bağımsız hareket etmektedirler. Hâlbuki birliklerin birlikte hareket etmeleri, özellikle hasat sezonunda uygun fiyatın belirlenmesinde önemli avantaj sağlayacaktır.

Sonuç olarak, kivide pazarlamanın birlikler aracılığıyla yapılması üreticilere büyük avantaj sağlayacaktır. Kivi üretici birlikleri, mali konularda sıkıntılar yaşamakta ve bundan dolayı son zamanlarda kapanma tehlikesi içindedirler. Tarımsal örgütlenmenin çiftçiler açısından önemli olduğu günümüzde, tarım politikası hedefleri içinde birliklere daha fazla yer verilmesi ve sürdürülebilirlik açısından maddi desteklerin yapılması üretici ve birliklerin beklentileri arasındadir.

\section{Kaynaklar}

Anonim, 2005. Türk Standard1, Kivi, TSE, TS 11306, Ankara.

Anonim, 2015. Bitkisel Üretim İstatistikleri. http://www.tuik.gov.tr. (Erişim tarihi: 27.04.2015).

Anonymous, 2015. Agricultural Production Data. http://faostat3.fao.org. (Erişim tarihi: 27.04.2015).

Aydoğan, M., Yulafçı, A., 2013. Samsun ilindeki tarımsal üretici örgütlerinin yapısal sorunlarının belirlenmesi. Proje sonuç raporu, Karadeniz Tarımsal Araştırma Enstitüsü, Samsun.

İnan, İ.H., Gülçubuk, B., Ertuğrul, C., Kantürer, E., Baran, E.A., Dilmen, Ö., 2000. Türkiye'de tarımda kırsal kesim örgütlenmesi. Türkiye Ziraat Mühendisliği V. Teknik Kongresi, Cilt I, 17-21 Ocak, Ankara, s. 145-175.

Köroğlu, S., 2003. Avrupa Birliğinde ve Türkiye'de tarımsal örgütlenme. Tarım ve Köyişleri Bakanlığı, Dış İlişkiler ve Avrupa Topluluğu Koordinasyon Dairesi Başkanlığı, AT uzmanlık tezi, Ankara.

Özdemir, G., Keskin, G., Özüdoğru, H., 2010. Türkiye'de ekonomik krizlere alternatif bir çözüm önerisi: Tarımda güçlü ve etkin üretici örgütlenme modeli. Türkiye IX. Tarım Ekonomisi Kongresi, Cilt I, 22-24 Eylül, Şanlıurfa, s. 518-525.

Rehber, E., 2007. Tarımda Örgütlenme ve Sorunları. http://erekonomi.com/orgut.pdf. (Erişim tarihi: 12.02.2015). 